\title{
NOTA FISCAL DO CONSUMIDOR ELETRÔNICA (NFC-e): PERCEPÇÃO DA VIABILIDADE DE UTILIZAÇÃO JUNTO ÀS EMPRESAS PRESTADORAS DE SERVIÇOS CONTÁBEIS DE TANGARÁ DA SERRA - MT
}

\author{
Márcio Íris de Morais ${ }^{1}$ \\ Ronison Rodrigues da Costa ${ }^{2}$
}

\begin{abstract}
RESUMO
Este trabalho teve por objeto a viabilidade de utilização da Nota Fiscal do Consumidor Eletrônica (NFC-e) junto aos contabilistas das empresas prestadoras de serviços contábeis de Tangará da Serra/MT. O objetivo foi demonstrar a percepção da viabilidade de utilização da NFC-e por empresas prestadoras de serviços contábeis de Tangará da Serra MT. Também se relacionou diretamente aos serviços prestados, sendo possível identificar, analisar e descobrir os fatores que proporcionam eventuais vantagens às empresas de serviços contábeis quanto à esta exigência do fisco. Para tanto, utilizou-se do método de estudo de campo, processo de amostragem não probabilística e aplicação de questionário fechado com os Contabilistas responsáveis por empresas prestadoras de serviços contábeis de Tangará da Serra/MT. Com um total de 33 contabilistas que responderam os questionários, a população da pesquisa compreende 49 (quarenta e nove) empresas de prestações de serviços contábeis ativas. O questionário foi aplicado à população no período de Abril de 2014 e obteve-se 33 (trinta e três) respostas. Verificou-se pela análise que $58 \%$ têm clientes que já utilizam a NFC-e. Destes $58 \%$ que utilizam, $65 \%$ deles o fazem pelo fato de serem obrigados e apenas $3 \%$ por voluntariedade. Com relação à percepção da viabilidade de utilização e aceitação dos contabilistas referente à NFC-e, verificou-se satisfação com as vantagens obtidas na prestação de serviços e possibilidades futuras.
\end{abstract}

Palavras-chave: Percepção, Aceitação, Viabilidade e NFC-e.

\section{ABSTRACT}

This study aimed to diagnose the perceived feasibility of using Invoice of Consumer Electronics ( NFC - e) with the accounting officers of companies providing financial services located in Tangara da Serra / MT . The objective was to demonstrate whether accountants from providing financial services Tangara da Serra / MT companies are already prepared for deployment imposed by SEFAZ / MT , Invoice of Consumer Electronics ( NFC - e) . Also directly related to quality of services, and can identify , analyze and discover the factors that provide satisfaction Counters on this IRS requirement . For this, we used the method of field study, non -probability sampling process and questionnaire enclosed with the barristers of providing accounting services Tangara da Serra / MT companies. With a total of 33 accountants who answer questionnaires , analyzes the city of Tangara da Serra - MT during the period April 2014 it was found that there are 49 ( forty nine ) companies benefit from active financial services, and that these questionnaires were applied in 33 ( thirty-three ), where we found that the 33 ( thirty-three ) companies provide accounting services , $58 \%$ of them have clients that already use NFC

\footnotetext{
${ }^{1}$ Orientador Professor do curso de Ciências Contábeis da Universidade do Estado de Mato Grosso (UNEMAT), "Campus" Universitário de Tangará da Serra, Mestre em Contabilidade pela Universidade do Vale do Rio dos Sinos (UNISINOS), marciomorais@ unemat.br.

${ }^{2}$ Acadêmico do curso de Ciências Contábeis, da Universidade do Estado de Mato Grosso (UNEMAT), "Campus" Universitário de Tangará da Serra, ronisonr@hotmail.com.
} 
-e. Regarding the perception of the feasibility of the use and acceptance of accountants regarding NFC and it was found that they are satisfied with the result of this deployment, even without much information from the tax authorities.

Keywords: Perception, Acceptance, and Feasibility-and NFC.

\title{
1. INTRODUÇÃO
}

Sabe-se, entretanto, que no mundo moderno internacionalizado, caracterizado pela era da informação, a informática está revolucionando as relações comerciais, e a Contabilidade, enquanto ciência inserida nesse contexto tem passado por significativa reestruturação (MARQUES, 2006, p. 57-62).

Girotto (2007), ressalta a necessidade do contabilista e demais profissionais da área contábil estarem preparados para as mudanças que estão por vir, bem como os envolvidos no âmbito de formação acadêmica.

Ressaltam Neto, Dias e Pinheiro (2009) que:

\begin{abstract}
A Contabilidade está diante de novos desafios causados pelas constantes mudanças no cenário econômico mundial onde a economia globalizada, o desenvolvimento do mercado de capitais internacional e o aumento dos investimentos estrangeiros geram a necessidade de utilização de normas e procedimentos que contribuam para reduzir as diferenças das informações contábeis entre os países (NETO; DIAS; PINHEIRO, 2009 p. 131-153).
\end{abstract}

A informática proporciona à contabilidade inúmeras facilidades, que vão desde o lançamento e processamento das informações até a geração dos relatórios que podem ser produzidos pelo sistema. No mundo moderno, as empresas estão percebendo a necessidade de serem cada vez mais abertas no que tange ao uso das informações (DIÓGENES, 2006).

O sistema de informação é de suma importância para a Ciência Contábil. Os contadores trabalham com informações e essas devem ter como características principais, a velocidade e a segurança, tendo em vista que além de o mundo ser dinâmico, o que exige que as decisões sejam tomadas a cada instante, as organizações, assim como as pessoas, necessitam estarem bem informadas, em tempo real (DIÓGENES, 2006).

A tecnologia de informação está cada vez mais presente no dia-a-dia das empresas e dos escritórios de contabilidade do Brasil, e um dos projetos do governo neste sentido diz respeito ao compartilhamento de notas fiscais de maneira eletrônica (TECNOSPEED DOSSIÊ NFC-e / 2013). 
O projeto da NFC-e teve sua primeira reunião de implantação no Brasil em agosto de 2012 que foi composto por 32 empresas varejistas dos estados Acre, Amazonas, Maranhão, Mato Grosso, Rio Grande do Norte, Rio Grande do Sul e Sergipe, com o objetivo de testar em ambiente de produção os servidores de NFC-e, que foram construídos inicialmente pelos estados de RS, MT e AM, de modo a antecipar problemas que poderiam impactar severamente os usuários no futuro, durante o período de massificação. (TECNOSPEED DOSSIÊ NFC-e / 2013).

Diversas reuniões foram feitas entre as empresas, que evoluíram consideravelmente com modelo proposto incialmente, com inovações de ordem técnica e muitas de ordem de processo, visando atenuar o impacto desse novo modelo de faturamento varejista brasileiro (TECNOSPEED DOSSIÊ NFC-e /2013). Este projeto que é denominado de NFC-e foi instituído pelo Ajuste do Sistema Nacional de Informações Econômicas e Fiscais (Sinief) $n^{\text {o }}$ 01/2013, que alterou o Ajuste Sinief n $n^{\text {0 }}$ 07/2005 Nota Fiscal Eletrônica (NF-e). (MINISTÉRIO DA FAZENDA, 2013). No estado de Mato Grosso, a NFC-e foi regulamentado pelo Decreto Estadual $n^{\circ} 1.877 / 2013$ e pela Portaria $n^{\circ} 77 / 2013$ (SEFAZ/MT, 2013).

As empresas que adotaram a contabilidade informatizada tiveram bons resultados e procuram cada vez mais melhorar esse processo (DIÓGENES, 2006). Para o autor, há algumas vantagens da contabilidade informatizada, como: Aumento da produtividade; Melhoria da qualidade dos serviços; Mais estimulo para os profissionais da área; Facilidade para a leitura prévia de relatórios; Facilidade de acesso às informações da empresa; Maior segurança das informações. Ainda, Diógenes (2006) salienta que estes são alguns dos aspectos positivos que justificam o uso da informática e consequente sistema digital pelas empresas, tanto na contabilidade quanto em outras áreas, levando-se sempre em conta as necessidades operacionais e organizacionais. Ainda, as empresas necessitam, além de um bom sistema de informações, devem ter uma melhor organização e estruturação de seus processos e suas atividades devem ser realizadas com eficiência.

Diante destas informações surge seguinte questionamento: Qual é a percepção da viabilidade de utilização da NFC-e na prestação de serviços por empresas prestadoras de serviços contábeis de Tangará da Serra - MT?

A pesquisa teve como objetivo, demonstrar a percepção da viabilidade de utilização da NFC-e na prestação de serviços por empresas prestadoras de serviços contábeis de 
Tangará da Serra - MT. Nesta pesquisa alguns objetivos específicos foram propostos: Contextualizar a Legislação vigente sobre a NFC-e; Identificar a percepção dos Contabilistas das empresas prestadoras de serviços contábeis de Tangará da Serra - MT, sobre a utilização da NFC-e na prática contábil; Verificar a percepção dos Contabilistas das empresas prestadoras de serviços contábeis de Tangará da Serra - MT, sobre os retornos pela utilização da NFC-e na prática contábil.

\section{REFERENCIAL TEÓRICO}

\subsection{Conceito da NFC-e}

A nota fiscal do consumidor eletrônica (NFC-e) é um novo modelo de documento fiscal, que por consequência dos avanços tecnológicos permite que uma operação de circulação de mercadorias seja emitida e armazenada eletronicamente, e esta nova nota fiscal do consumidor eletrônica (NFC-e) modelo (65), existirá somente em meio eletrônico (TECNOSPEED DOSSIÊ NFC-e /2013).

Considera-se NFC-e o documento emitido e armazenado eletronicamente, de existência apenas digital, com o intuito de documentar operações e prestações relativas ao ICMS, em venda presencial, no varejo, ao consumidor final, cuja validade jurídica é garantida pela assinatura digital do emitente e pela Autorização de Uso concedida pela Secretaria de Estado de Fazenda, antes da ocorrência do fato gerador (SEFAZ/MT, 2013).

A NFC-e propõe o estabelecimento de um padrão nacional de documento fiscal eletrônico, baseado nos padrões técnicos de sucesso da Nota Fiscal Eletrônica modelo 55, todavia adequado às particularidades do varejo. A adoção da NFC-e ficará a critério de cada Unidade federada, podendo conviver com outros mecanismos de controle fiscais atualmente existentes, como Emissor de Cupom Fiscal - ECF e SAT Fiscal (TECNOSPEED DOSSIÊ NFC-e /2013).

Participaram do projeto piloto da NFC-e representantes de Secretarias de Fazenda Estaduais dos Estados do Acre, Amazonas, Mato Grosso, Maranhão, Rio Grande do Sul, Rio Grande do Norte e Sergipe; da Receita Federal e de um grupo de 32 empresas voluntárias, representativas de distintos segmentos do varejo (TECNOSPEED DOSSIÊ NFC-e 12013). A coordenação nacional do projeto NFC-e está a cargo do Encontro Nacional de Coordenadores e Administradores Tributários Estaduais (ENCAT), fórum de coordenação fiscal e de compartilhamento de melhores práticas das Administrações 
Tributárias Estaduais e que é também responsável pela implantação de outros projetos de relevância para o país, tais como a NF-e, CT-e e projeto Brasil-ID (TECNOSPEED DOSSIÊ NFC-e /2013).

Logo, as empresas obrigadas e aquelas que porventura optarem por utilizá-la voluntariamente, terão que substituir os seguintes documentos: (SEFAZ/MT, 2013).

- Notas Fiscais de Venda a Consumidor modelo 2;

- Cupom Fiscal emitido por equipamento Emissor de Cupom Fiscal (ECF);

- Notas Fiscais modelo 1 ou 1-A, quando utilizada na venda a varejo;

- Nota Fiscal Eletrônica, modelo 55, quando utilizada na venda a varejo.

O Ajuste SINIEF no 07/2005 que instituiu a validade jurídica da NF-e, em seu Parágrafo Único da Cláusula Primeira, determina o conceito legal da NF-e como sendo:

\footnotetext{
Um documento emitido e armazenado eletronicamente, de existência apenas digital, com o intuito de documentar operações e prestações, cuja validade jurídica é garantida pela assinatura digital do emitente e autorização de uso Pela administração tributária da unidade federada do contribuinte, antes da ocorrência do fato gerador. (MINISTÉRIO DA FAZENDA, 2013).
}

Assim, pelo fato da NFC-e seguir as normas da NF-e também constitui o mesmo entendimento mencionado para NF-e, salienta-se que a NFC-e representa uma imposição da legislação antes de ser uma aplicação das inovações tecnológicas existentes, pois as empresas que têm sua atividade obrigada à utilização da NFC-e terão que adotá-la no prazo para não sofrerem nenhuma punição ao descumprimento das normas legais exigidas (MINISTÉRIO DA FAZENDA, 2013).

\subsection{Objetivo, Vantagens e Desvantagens da NFC-e}

O objetivo da NFC-e em primeiro momento visa substituir gradativamente os seguintes documentos: (SEFAZ/MT, 2013).

- Notas Fiscais modelo 1 e modelo 1-A quando utilizada na venda a varejo;

- Notas Fiscais modelo 2;

- Cupom Fiscal emitido por equipamentos Emissor de Cupom Fiscal (ECF);

- Notas Fiscais Eletrônicas modelo 55 quando utilizadas na venda a varejo; 
Porém o objetivo principal do projeto da NFC-e encontra-se descrito no sítio eletrônico do Ministério da Fazenda (2013):

O Projeto NFC-e tem como objetivo a implantação de um modelo nacional de documento fiscal eletrônico que venha substituir a sistemática atual de emissão do documento fiscal em papel, com validade jurídica garantida pela assinatura digital do remetente, simplificando as obrigações acessórias dos contribuintes. (Ministério da Fazenda, 2013).

A implantação do projeto da NFC-e representou um enorme avanço para facilitar a vida do contribuinte, do consumidor e o controle do fisco sobre as operações e prestações tributadas pelo Imposto sobre Operações Relativas à Venda de Mercadorias destinadas ao Consumidor Final (TECNOSPEED DOSSIÊ NFC-e, 2013).

As Vantagens, conforme a apresentação do projeto pelo Sinief $n^{\circ}$ 01/2013 NFC-e, ficou evidente que a adesão deste documento promete trazer benefícios para todos os integrantes do processo, que são os contribuintes emitentes, o consumidor final, os administradores tributários e a sociedade em geral.

Conforme publicado no Ajuste Sinief $n^{\circ}$ 01/2013 que alterou o Ajuste Sinief $n^{\circ}$ 07/2005 (MINISTERIO DA FAZENDA, 2013) e regulamentado no Estado de Mato Grosso pelo Decreto Estadual no 1.877/2013 e Portaria n 77/2013(SEFAZ/MT, 2013), será de grande valia para os escritórios na questão de importação e conferencia das NFC-e, pois terá uma redução no tempo de espera pelo seu cliente, pois não necessitará de esperá-lo encaminhar o movimento no final de cada mês ao escritório, pois o mesmo poderá simplesmente encaminhar os arquivos XML que será gerado automaticamente quando efetuar a Venda ao Consumidor Final.

Dentre as desvantagens pode-se constatar a seguinte: $O$ contribuinte emissor da NFC-e e os Contadores ainda possuem dúvidas sobre o que vem sendo publicado por órgãos organizadores do projeto da NFC-e, a respeito da segurança e da não violação de informações contidas nas Notas Fiscais do Consumidor Eletrônicas (TECNOSPEED DOSSIÊ NFC-e /2013).

Também, outra desvantagem, é quanto ao cancelamento da NFC-e, pois o mesmo só poderá ser efetuado quando: 
- Solicitar o cancelamento da NFC-e, mediante Pedido de Cancelamento de NFC-e, transmitido à Secretaria de Estado de Fazenda, quando, observadas as demais disposições da legislação pertinente, cumulativamente:

- Não tenha ocorrido a circulação da mercadoria ou a prestação do serviço;

- Não tenha decorrido período de tempo superior a 24 (vinte e quatro) horas, contadas do momento da concessão da Autorização de Uso da NFC-e correspondente; (efeitos a partir de 15 de outubro de 2013) (Nova redação dada pela Port. 276/13) disponível no sítio da SEFAZ/MT.

\subsection{Obrigatoriedade, emissão e requisitos da NFC-e}

A adoção da NFC-e não é obrigatória para todo tipo de atividade. Em regra, toda empresa que efetuar venda a varejo para consumidor final está obrigada emissão de cupom fiscal. No Estado de Mato Grosso as obrigações estão estabelecidas nas seguintes condições, conforme disposto no art. 198-G-1 do Regulamento do ICMS de Mato Grosso (RIMS/MT), disponível no sítio da SEFAZ/MT.

\section{A partir de 01/10/2013: (SEFAZ/MT, 2013)}

Será obrigatório o uso da NFC-e para as empresas que, a partir desta data requerem inscrição no Cadastro do Estado ou para contribuintes que, voluntariamente, requererem credenciamento para sua utilização.

\section{A partir de 01/07/2014 para as seguintes situações; (SEFAZ/MT, 2013)}

a) para os contribuintes, participantes da implantação do uso da NFC-e, de que trata o $\$ 13$ do artigo 198-G;

b) para os estabelecimentos que, no exercício financeiro de 2013, auferirem faturamento superior a $\mathrm{R} \$ 2.520 .000,00$ (dois milhões quinhentos e vinte mil reais);

\section{A partir de 01/08/2014; (SEFAZ/MT, 2013)}

Todos os contribuintes que ainda não estiverem obrigados, com exceção do MEI enquadrado no Cadastro de Contribuintes como optante pelo Simples Nacional.

A emissão da NFC-e é feita pelo próprio contribuinte que efetuar operações comerciais de venda a consumidor final, e nas operações onde necessita de entrega em domicilio (delivery), para entregas de produtos provenientes de pizzarias, lanchonetes, restaurantes, farmácia, floriculturas, etc e apenas para operações dentro do Estado. Netas hipóteses serão exigidas na NFC-e a identificação do consumidor (nome, CPF/CNPJ se consumidor final) e do endereço de entrega. (SEFAZ/MT, 2013). 
Os requisitos para emissão e impressão da NFC-e (SEFAZ/MT, 2013), são:

- Possuir certificado digital no padrão ICP-Brasil, contendo o CNPJ da empresa;

- Desenvolver, adquirir um software emissor de NFC-e ou utilizar o emissor gratuito disponibilizado pela SEFAZ/MT;

- Solicitar o token de produção disponível no sitio da SEFAZ/MT;

- Estar com a inscrição estadual regular;

- Ter impressoras não fiscal, térmicas ou a laser;

- Utilizar qualquer tipo de papel, exceto papel jornal, respeitados, ainda, os seguintes requisitos: (v. inciso III do $§ 11$ da cláusula nona do Ajuste SINIEF 7/2005, acrescentado pelo Ajuste SINIEF 11/2013 - efeitos a partir de $1^{\circ}$ de setembro de 2013) (Nova redação dada pela Port. 257/13).

- Largura mínima de $58 \mathrm{~mm}$ e altura mínima suficiente para conter todas as seções especificas no 'Manual de Orientação do Contribuinte' da NF-e;

- Utilização, para impressão, de tecnologia que garanta a legibilidade das informações impressas por, no mínimo de 6 (seis) meses;

- Deverá conter o código bidimensional, conforme padrão estabelecido no 'Manual de Orientação do Contribuinte' da NF-e; (cf. inciso IV do $§ 11$ da cláusula nona do Ajuste SINIEF 7/2005, acrescentado pelo Ajuste SINIEF 11/2013 - efeitos a partir de $1^{\circ}$ de setembro de 2013) (nova redação dada pela port. 257/2013);

- Deverá refletir o conteúdo dos campos do arquivo da NFC-e;

- Deverá conter o número de protocolo emitido pela Secretaria de Estado de Fazenda quando da concessão da Autorização de Uso da NFC-e, ressalvada da hipótese de contingência prevista no artigo 18;

- Deverá conter impressa a mensagem: "Não permite aproveitamento de crédito de ICMS"

\section{METODOLOGIA}

Metodologia segundo Andrade (2010, p. 117), “é o conjunto de métodos ou caminhos que são percorridos na busca do conhecimento".

\subsection{Metodologia da pesquisa}


Sobre os Procedimentos Metodológicos e Técnicos para Severino (2002, p.162), é exposto como: "Entende-se por métodos os procedimentos mais amplos de raciocínio, enquanto técnicas são procedimentos mais restritos que operacionalizam os métodos, mediante emprego de instrumentos adequados".

A metodologia aplicada à pesquisa de conclusão de curso foi desenvolvida com os métodos, bibliográfico, exploratório e pesquisa de campo. Possibilitou alcançar o resultado da percepção da viabilidade de utilização NFC-e junto aos contabilistas das empresas prestadoras de serviços contábeis de Tangará da Serra/MT. Foram pesquisados temas sobre o assunto e aplicados questionários fechados de onde foi possível coletar os dados, quantificá-los e analisá-los no período de Abril de 2014.

Foram pesquisados temas sobre o assunto junto à internet, junta a Secretaria de Fazenda do Estado Mato Grosso e também legislação própria da implantação e utilização da NFC-e no período de Setembro de 2013 à Maio de 2014. Fundamentado na literatura pesquisada, foi realizado questionário com perguntas fechadas, composto por 10 (dez) questões. Os dados coletados foram realizados através de uma survey, disponibilizado à população no período de 24/04/2014 a 25/04/2014, nas empresas prestadoras de serviços contábeis de Tangará da Serra - MT. Anexo ao questionário seguiu-se uma carta de apresentação onde se descrevia, resumidamente, a proposta da pesquisa. Foi aplicado para 35 (trinta e cinco) contabilistas das empresas prestadoras de serviços contábeis de Tangará da Serra- MT.

\subsection{Delimitação do estudo}

A pesquisa delimitou-se exclusivamente aos contabilistas das empresas prestadoras de serviços contábeis de Tangará da Serra/MT, de onde os dados foram coletados.

Conforme Marconi e Lakatos (2003), “a população ou universo de uma pesquisa é constituído pelo conjunto de elementos que serão pesquisados tendo pelo menos uma característica em comum”. Sendo assim a população constituiu-se por 49 (quarenta e nove) contabilistas das empresas prestadoras de serviços contábeis ativas de Tangará da Serra MT. Inicialmente em consulta ao site do CRC/MT, foi verificada a existência de uma lista com os registros de 78 (setenta e oito) empresas sendo que destas, 49 (quarenta e nove) encontram-se Ativas e 29 (vinte e nove) Inativas. Localizou-se 35 (trinta e cinco), nas quais obteve-se o retorno de 33 (trinta e três). 
O tipo de delineamento utilizado para a primeira parte da pesquisa foi por meio de bibliografia especializada, que de acordo com Gil (2002), “caracteriza a pesquisa bibliográfica como sendo desenvolvida a partir de material existente”. Dessa forma, quanto aos procedimentos de coleta de dados, a referida pesquisa se classifica como bibliográfica, pois foram utilizados livros, revistas, informativos, artigos científicos e sites especializados, sendo possível assim o estudo da literatura e da documentação para melhor compreensão do assunto abordado. A segunda parte da pesquisa é do tipo descritiva, que de acordo com Gil (2002), “esse tipo de pesquisa procura verificar as opiniões e atitudes de determinada população, bem como descrever as características de um grupo ou fenômeno", sendo realizado por meio de levantamento ou survey, com enfoque quantitativo.

\subsection{Tratamento dos dados}

Os dados obtidos foram armazenados em um banco de dados e, após, quantificados e submetidos a análises estatísticas. O tratamento dos dados foi realizado por meio da utilização do programa Microsoft Excel 2013®.

Os resultados foram tabulados e utilizou-se análise descritiva dos dados, através da construção de tabelas de frequência simples e apuração da média, permitindo-se uma análise quantitativa dos dados por distribuição de frequências, que, para Sampieri (2010, p.416), "é um conjunto de pontuações ordenadas em suas respectivas categorias". Conforme o autor, ainda poderá ser apresentado para melhor visualização, através de histogramas e gráficos que melhor componha a visualização e interpretação dos resultados.

\subsection{Estudo com os contabilistas das empresas prestadoras de serviços contábeis de Tangará da Serra - MT.}

O questionário aplicado aos contabilistas das empresas prestadoras de serviços contábeis de Tangará da Serra - MT foram compostos por questões objetivas e separadas em duas partes, contendo 10 perguntas de múltipla escolha. O objetivo da primeira parte é identificar a percepção dos contabilistas das empresas prestadoras de serviços contábeis de Tangará da Serra - MT, sobre a utilização da NFC-e na prática contábil. E na segunda parte, verificar a percepção dos contabilistas das empresas prestadoras de serviços contábeis de Tangará da Serra - MT, sobre os retornos pela utilização da NFC-e na prática contábil. 


\section{DISCUSSÃO E ANÁLISE DOS RESULTADOS}

\subsection{Perfil da amostra}

A população de empresas prestadoras de serviços contábeis em Tangará da Serra MT, conforme relatório existente no site do CRC/MT, soma um total de 78 (setenta e oito).

Gráfico 1 - Empresas de serviços contábeis de Tangará da Serra - MT.

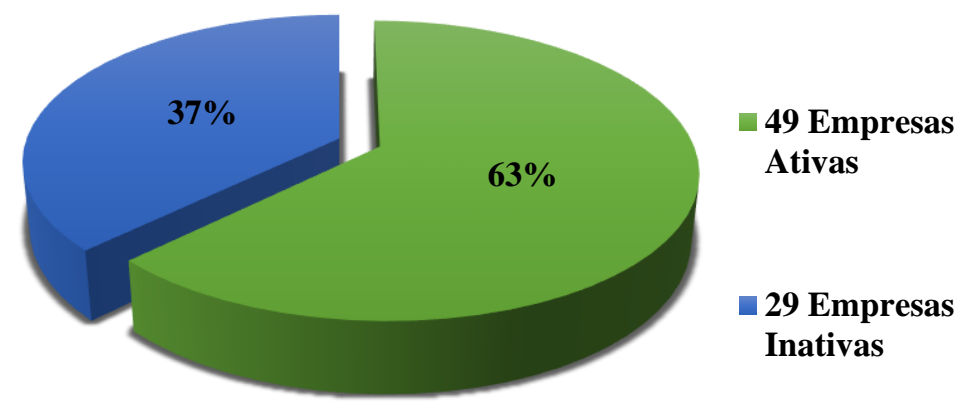

Os dados coletados junto ao site do CRC/MT, demonstram que das 78 (setenta e oito) empresas de serviços contábeis na cidade de Tangará da Serra - MT, 49 (quarenta e nove) encontra-se ativas e 29 (vinte e nove) inativas.

Gráfico 2 - Empresas de serviços contábeis ativas de Tangará da Serra - MT.
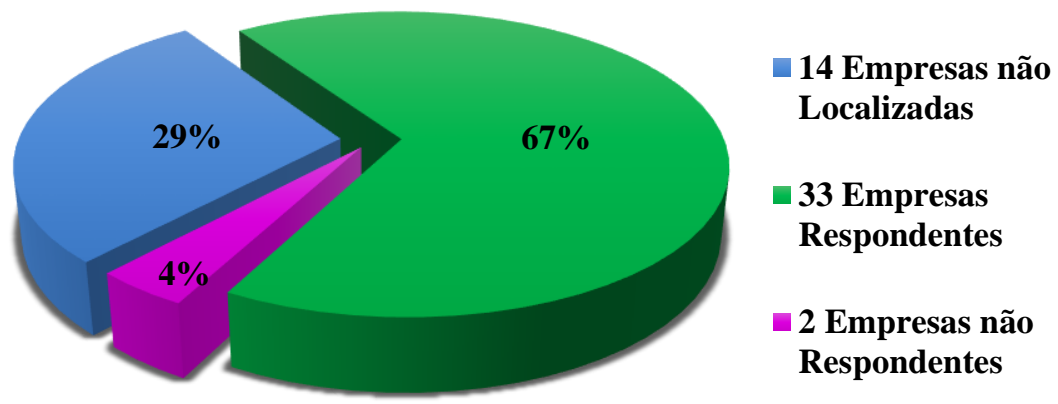

Conforme apresentado no gráfico, das 49 (quarenta e nove) empresas, 14 (quatorze) não foram localizadas, sendo aplicado apenas em 35 (trinta e cinco) empresas, na qual a quantidade total de questionários respondidos foi de 33 (trinta e três) e 2 (duas) empresas não responderam.

4.2 Percepção dos contabilistas das empresas prestadoras de serviços contábeis de Tangará da Serra - MT, sobre a utilização da NFC-e na prática contábil. 
Nas questões de 1 (um) a 7 (sete), buscou-se saber dos contabilistas das empresas prestadoras de serviços contábeis, a sua percepção quanto a utilização da NFC-e na prática contábil.

Primeiramente, conforme demonstrado no gráfico 3, foi questionado aos contabilistas das empresas de prestação de serviços contábeis de Tangará da Serra - MT, se algum(s) cliente(s) de sua empresa utiliza NFC-e.

Gráfico 3 - Algum(s) cliente(s) de sua empresa utiliza Nota Fiscal do Consumidor Eletrônica (NFC-e)?

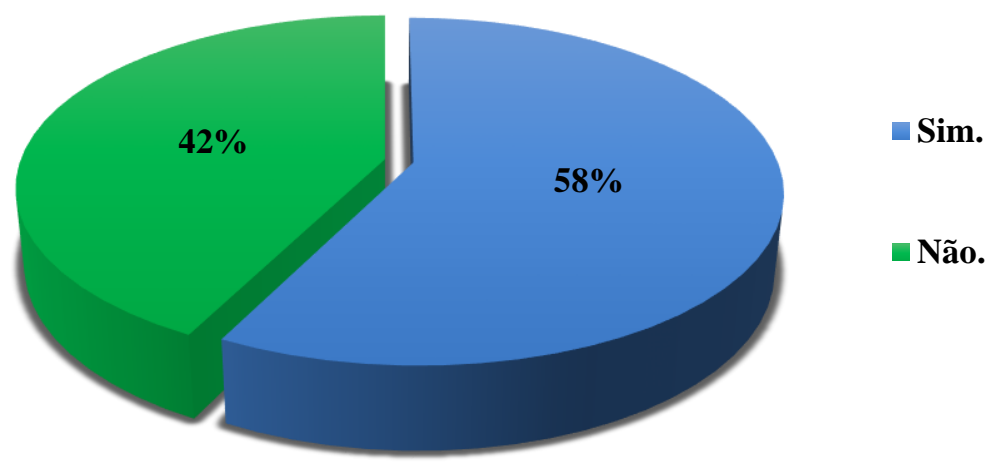

Dos 33 contabilistas entrevistados, 58\% disse ter cliente(s) que utiliza NFC-e e $42 \%$ dos entrevistados disseram que ainda não tem cliente(s) que utiliza a NFC-e. Demonstra-se assim, que mais de $50 \%$ dos cliente(s) das empresas prestadoras de serviços contábeis de Tangará da Serra - MT questionados fazem a utilização da NFC-e.

No gráfico 4, apresenta-se o resultado do questionamento para contabilistas das empresas de prestação de serviços contábeis de Tangará da Serra - MT, o motivo de seu(s) cliente(s) terem implantado a NFC-e ou qual motivo levará a implantação da NFC-e.

Gráfico 4 - Qual o principal motivo da implantação da NFC-e na(s) empresa(s) do(s) seu(s) cliente(s)? 


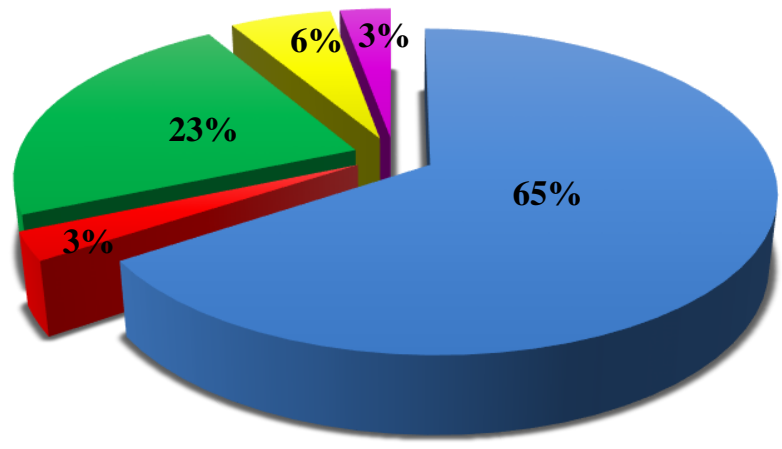

匹 Obrigatoriedade.

- Voluntariedade.

• Sistematização dos dados.

Diminuição de gastos.

- Outros.

Diante das alternativas apresentada, dos 33 contabilistas entrevistados, 65\% disseram ter como motivo a obrigatoriedade do(s) seu(s) cliente(s) de utilizar a NFC-e; já $23 \%$ disseram que foi pela sistematização de dados, $6 \%$ responderam que foi pelo fato da diminuição dos gastos, com o mesmo percentual, sendo este de $3 \%$ para cada alternativa, disseram ser por voluntariedade ou outros motivos. Resultados estes, onde demonstram que é superior a 50\% a utilização e implantação da NFC-e por cliente(s) das empresas prestadoras de serviços contábeis em Tangará da Serra - MT, pelo fato da obrigatoriedade e não por ouras alternativas conforme demonstrado.

Em seguida, foi questionado aos contabilistas das empresas de prestação de serviços contábeis de Tangará da Serra - MT, se com a utilização ou possibilidade de utilizar a NFC-e por parte do(s) seu(s) cliente(s), o arquivo XML (Extensible Markup Language) disponibilizado trará facilidade na execução dos lançamentos fiscais e contábeis, conforme demonstrado no gráfico5:

Gráfico 5 - Com a utilização ou possibilidade de uso da NFC-e na(s) empresa(s) do(s) seu(s) cliente(s) o arquivo XML disponibilizado facilita ou facilitará a execução dos lançamentos fiscais e contábeis?

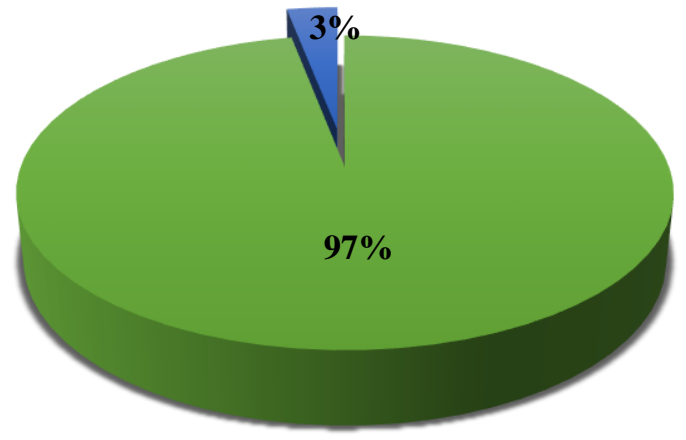

\begin{abstract}
Sim, pois reduz-se tempo na execução dos serviços, bem como, erros de escrituração, devido à importação automática do arquivo XML.
\end{abstract}
- Não, por falta de adaptação do sistema utilizado pelo escritório contábil para importar e extrair as informações do arquivo XML.

Diante das alternativas sim ou não apresentadas, dos 33 contabilistas entrevistados, 97\% disseram que facilita ou facilitará os lançamentos fiscais e contábeis; já 3\% disseram que não. Resultados estes, que demonstra a superioridade de $90 \%$ dos contabilistas 
entrevistados, dizendo que a facilidade, redução do tempo na execução dos serviços e redução de erros, pode ou poderá sim serem sanadas através do XML enviado por seu(s) cliente(s).

Abaixo, demonstra-se na tabela 1, os resultados das respostas efetuadas por contabilistas responsáveis pelas empresas de serviços contábeis de Tangará da Serra - MT, sobre a importância dos impactos com a implantação da NFC-e para o(s) cliente(s). Disponibilizou-se escala de 1 a 5, onde: 1- Sem Importância (SI); 2- Pouca Importância (PI) 3- Neutro (N); 4- Muita Importância (MI) e 5- Extrema Importância (EI).

Nesta questão as alternativas eram: 1) Consumo de papel será reduzido com impacto positivo ao meio ambiente; 2) de empregos na aérea de tecnologia em informática; 3) Facilitou a fiscalização, aumentando a arrecadação de impostos e diminuindo a sonegação; 4) Diminuiu os custos com equipamentos emissor de Cupom Fiscal; 5) Não houve benefícios.

Tabela - 1 a importância dos impactos com a implantação da NFC-e para o(s) cliente(s).

\begin{tabular}{|c|c|c|c|c|c|c|c|}
\hline ALTERNATIVAS & $(\mathrm{SI})$ & \multicolumn{1}{c}{$(\mathrm{PI})$} & $(\mathrm{N})$ & \multicolumn{1}{c|}{$(\mathrm{MI})$} & \multicolumn{1}{c|}{ (EI) } & TOTAL \\
\hline 1 & $\mathbf{2 4 , 2 4 \%}$ & $\mathbf{1 5 , 1 5 \%}$ & $\mathbf{1 2 , 1 2 \%}$ & $\mathbf{2 4 , 2 4 \%}$ & $\mathbf{2 4 , 2 4 \%}$ & $\mathbf{1 0 0 \%}$ \\
\hline 2 & $\mathbf{3 6 , 3 6 \%}$ & $\mathbf{1 2 , 1 2 \%}$ & $\mathbf{3 0 , 3 0 \%}$ & $\mathbf{1 2 , 1 2 \%}$ & $\mathbf{9 , 0 9 \%}$ & $\mathbf{1 0 0 \%}$ \\
\hline 3 & $\mathbf{9 , 0 9 \%}$ & $\mathbf{6 , 0 6 \%}$ & $\mathbf{2 4 , 2 4 \%}$ & $\mathbf{1 2 , 1 2 \%}$ & $\mathbf{4 8 , 4 8 \%}$ & $\mathbf{1 0 0 \%}$ \\
\hline 4 & $\mathbf{2 7 , 2 7 \%}$ & $\mathbf{2 1 , 2 1 \%}$ & $\mathbf{1 5 , 1 5 \%}$ & $\mathbf{6 , 0 6 \%}$ & $\mathbf{3 0 , 3 0 \%}$ & $\mathbf{1 0 0 \%}$ \\
\hline 5 & $\mathbf{7 2 , 7 3 \%}$ & $\mathbf{6 , 0 6 \%}$ & $\mathbf{6 , 0 6 \%}$ & $\mathbf{0 , 0 0 \%}$ & $\mathbf{1 5 , 1 5 \%}$ & $\mathbf{1 0 0 \%}$ \\
\hline
\end{tabular}

Foi possível perceber que a primeira alternativa obteve um percentual de 39,39\% dos contabilistas que disseram ser sem ou de pouca importância, a redução do consumo de papel com a implantação da NFC-e; Porem para 48,48\% dos contabilistas é de muita ou extrema importância, a redução do consumo de papel com a implantação da NFC-e;

Na segunda alternativa apresentou que $48,48 \%$ dos contabilistas acreditam sem ou de pouca importância, a oportunidade de emprego na aérea de tecnologia em informática com a implantação da NFC-e; 30,30\% disseram não ser nem sem importância e nem ter importância, estão neutros a está questão; e apenas $21,21 \%$ dos contabilistas acham de muita ou extrema importância, a oportunidade de emprego na área de tecnologia em informação com a implantação da NFC-e.

A terceira alternativa apresentou que $15,15 \%$ dos contabilistas acham sem ou de pouca importância, a facilitação da fiscalização, aumento da arrecação e a diminuição da sonegação com a implantação da NFC-e; $24,24 \%$ disseram não ser nem sem importância e nem ter importância, está questão; porem $60,60 \%$ dos contabilistas acham de muita ou extrema importância, a facilitação da fiscalização, aumento da arrecação e a diminuição da sonegação com a implantação da NFC-e.

Alternativa quarta apresentou que 48,48\% dos contabilistas acreditam sem ou de pouca importância, a diminuição dos custos com equipamentos emissores de cupom fiscal a partir da implantação da NFC-e; 15,15\% disseram não ser, nem sem importância e nem ter importância está questão; e 36,36\% dos contabilistas acham de muita ou extrema importância, a diminuição dos custos com equipamentos emissores de cupom fiscal a partir da implantação da NFC-e.

Quinta alternativa apresentou que 78,79\% dos contabilistas acham sem ou de pouca importância, dizer que não houve benefícios com a implantação da NFC-e; 6,06\% disseram 
não ser nem sem importância e nem ter importância está questão; e 15,15\% dos contabilistas acham de muita ou extrema importância, que com a implantação da NFC-e não houve benefícios.

A próxima questão, procurava saber dos contabilistas das empresas de prestação de serviços contábeis de Tangará da Serra - MT, se a sua empresa de prestação de serviços contábeis encontrou ou acredita que encontrará dificuldade(s) na utilização da NFC-e disponibilizada por seu(s) cliente(s) e, os resultados foram apresentados no gráfico 6:

Gráfico 6 - Sua empresa de prestação de serviços contábeis encontrou ou acredita que encontrará dificuldade(s) na utilização da NFC-e disponibilizada por seu(s) cliente(s)?

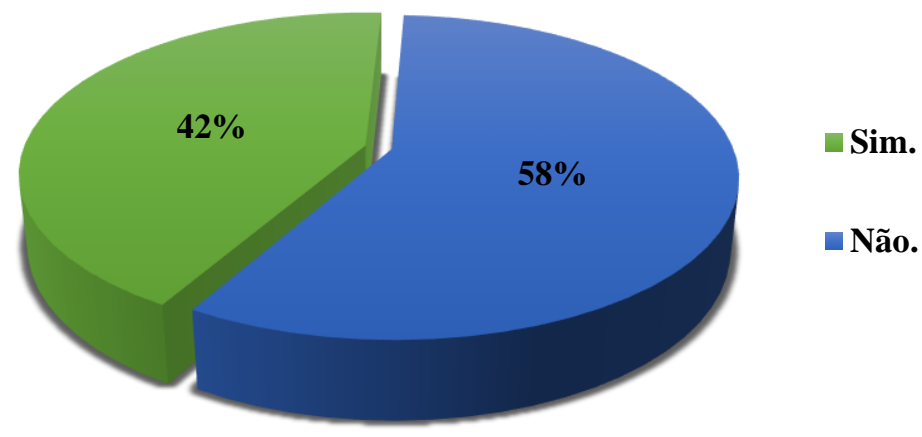

Diante das alternativas sim ou não apresentadas, dos 33 contabilistas entrevistados, $58 \%$ que correspondem a 19 entrevistados, disseram que não encontraram ou acredita não encontrar dificuldades; já $42 \%$ que correspondem a 14 entrevistados disseram sim, que encontraram e acredita encontrar dificuldades. Resultados estes, que mostra um equilíbrio dos contabilistas entrevistados, dizendo que encontrou ou poderá encontrar dificuldades na utilização da NFC-e disponibilizada por seu(s) cliente(s).

Na questão a seguir, gráfico 7, foi questionado aos contabilistas das empresas de prestação de serviços contábeis de Tangará da Serra - MT que responderam sim na questão anterior, qual procedimento teve mais dificuldade(s) com relação a disponibilização da NFC-e por parte de seu(s) Cliente(s).

Gráfico 7 - Se sim, qual procedimento teve mais dificuldade(s):

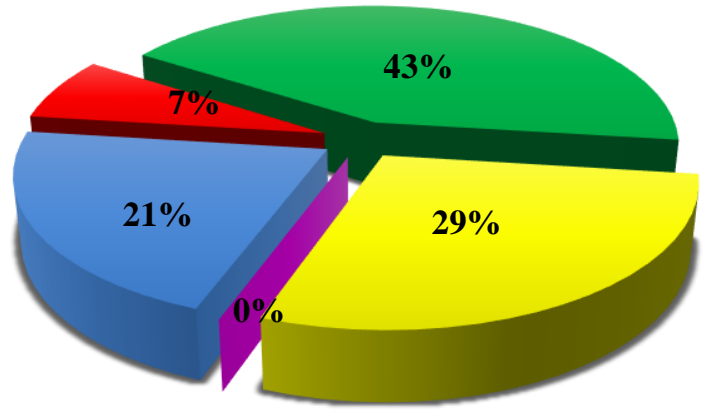

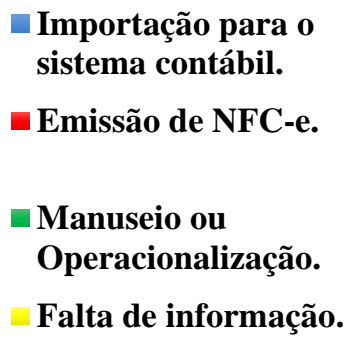

- Outros. 
Dos 33 contabilistas entrevistados, 43\% disseram ter encontrado dificuldade(s) no manuseio ou operacionalização; já $29 \%$ disseram que foi pela falta de informação; $21 \%$ responderam que foi na importação para o sistema contábil; 7\% disseram que encontraram dificuldades na emissão da NFC-e. Resultados estes, onde demonstram que a maioria dos contabilista encontrou dificuldades no manuseio e operacionalização, seguido da falta de informação e importação para o sistema contábil, pois não teve nem um tipo de informação clara e treinamento aos contabilistas por parte da SEFAZ/MT na implantação da NFC-e aos contribuintes do Estado de Mato Grosso.

Abaixo, demonstra na tabela 2, os resultados das respostas efetuadas por contabilistas responsáveis pelas empresas de serviços contábeis de Tangará da Serra - MT, sobre a dificuldade que o profissional contábil tem ou terá com a implantação da NFC-e ao(s) cliente(s). Disponibilizou-se escala de 1 a 5, onde: 1- Sem Dificuldade (SD); 2- Pouca Dificuldade (PD) 3- Neutro (N); 4- Muita Dificuldade (MD) e 5- Extrema Dificuldade (ED).

Nesta questão as alternativas eram: 1) Aumento das obrigações acessórias; 2) Investir em tecnologia para o escritório; 3) Qualificação contínua dos colaboradores também na área de informação, sistemas e novas tecnologias; 4) Tarefa implícita de repassar as normatizações da NFC-e aos clientes, além de auxiliar os microempresários na adequação da implantação na legislação; 5) Conhecimento constante das alterações ocorridas na legislação.

Tabela - 2 a dificuldade que o profissional tem ou terá com a implantação da NFC-e ao(s) cliente(s):

\begin{tabular}{|c|c|c|c|c|c|c|c|}
\hline ALTERNATIVAS & $(\mathrm{SD})$ & $(\mathrm{PD})$ & $(\mathrm{N})$ & \multicolumn{1}{c|}{$(\mathrm{MD})$} & $\mathbf{3})$ & \multicolumn{1}{c|}{ TOTAL } \\
\hline 1 & $\mathbf{4 5 , 4 5 \%}$ & $\mathbf{1 5 , 1 5 \%}$ & $\mathbf{1 2 , 1 2 \%}$ & $\mathbf{3 , 0 3 \%}$ & $\mathbf{2 4 , 2 4 \%}$ & $\mathbf{1 0 0 \%}$ \\
\hline 2 & $\mathbf{4 8 , 4 8 \%}$ & $\mathbf{2 4 , 2 4 \%}$ & $\mathbf{1 2 , 1 2 \%}$ & $\mathbf{6 , 0 6 \%}$ & $\mathbf{9 , 0 9 \%}$ & $\mathbf{1 0 0 \%}$ \\
\hline 3 & $\mathbf{2 7 , 2 7 \%}$ & $\mathbf{1 5 , 1 5 \%}$ & $\mathbf{2 7 , 2 7 \%}$ & $\mathbf{1 2 , 1 2 \%}$ & $\mathbf{1 8 , 1 8 \%}$ & $\mathbf{1 0 0 \%}$ \\
\hline 4 & $\mathbf{3 , 0 3 \%}$ & $\mathbf{9 , 0 9 \%}$ & $\mathbf{1 8 , 1 8 \%}$ & $\mathbf{9 , 0 9 \%}$ & $\mathbf{6 0 , 6 1 \%}$ & $\mathbf{1 0 0 \%}$ \\
\hline 5 & $\mathbf{1 8 , 1 8 \%}$ & $\mathbf{6 , 0 6 \%}$ & $\mathbf{1 5 , 1 5 \%}$ & $\mathbf{2 1 , 2 1 \%}$ & $\mathbf{3 9 , 3 9 \%}$ & $\mathbf{1 0 0 \%}$ \\
\hline
\end{tabular}

A primeira alternativa apresentou um percentual de $60,60 \%$ dos contabilistas que disseram sem ou pouca dificuldade, o aumento das obrigações acessórias com a implantação da NFC-e; $12,12 \%$ estão neutros com relação a está questão; Apenas 27,27\% dos contabilistas disseram que é de muita ou extrema dificuldade o aumento das obrigações acessórias com a implantação da NFC-e;

$\mathrm{Na}$ segunda alternativa que se refere a investir em tecnologia para o escritório, $72,72 \%$ dos contabilistas acreditam que é sem ou pouca dificuldade; $12,12 \%$ estão neutros com relação a está questão; Apenas $15,15 \%$ dos contabilistas disseram que é de muita ou extrema a dificuldade de investir em tecnologia para o escritório com a implantação da NFC-e;

A terceira alternativa trata-se, da qualificação contínua dos colaboradores também na área de informação, sistemas e tecnologias, apresentou que $42,42 \%$ dos contabilistas acham sem ou de pouca dificuldade esta tarefa; $27,27 \%$ estão neutros com relação a está questão; porem 30,30\% dos contabilistas acham de muita ou extrema dificuldade.

A Quarta alternativa, abordou a questão da dificuldade de repassar as normatizações da NFC-e aos clientes, além da dificuldade de auxiliar os microempresários na adequação da implantação da NFC-e, apenas $12,12 \%$ dos contabilistas acham sem ou de pouca 
dificuldade efetuar o que foi questionado; $18,18 \%$ disseram, nem sem dificuldade e nem ter dificuldade a está questão; porem $69,70 \%$ dos contabilistas acham de muita ou extrema dificuldade repassar as informações aos seus clientes; até mesmo por que os próprios contabilistas não receberam estas informações de forma adequadas dos órgãos responsáveis pela implantação da NFC-e.

Quinta alternativa perguntou a dificuldade com relação ao conhecimento das constantes alterações ocorridas na legislação, e 24,24\% dos contabilistas acham sem ou de pouca dificuldade essas atualizações; $15,15 \%$ disseram não ser nem sem dificuldade e nem ter dificuldade está questão; já a maioria que representa $60,60 \%$ dos contabilistas acham de muita ou extrema dificuldade o conhecimento das constantes alterações ocorridas na legislação.

\subsection{Verificar a percepção dos contabilistas das empresas prestadoras de serviços contábeis de Tangará da Serra - MT, sobre os retornos pela utilização da NFC-e na prática contábil.}

Na questão demonstrada no gráfico 8 , foi questionado aos contabilistas das empresas de prestação de serviços contábeis de Tangará da Serra - MT se com a utilização da NFCe, acredita que sua empresa de prestação de serviços contábeis conseguirá maior participação no mercado.

Gráfico 8 - Com a utilização da NFC-e, acredita que sua empresa de prestação de serviços contábeis conseguirá maior participação no mercado?

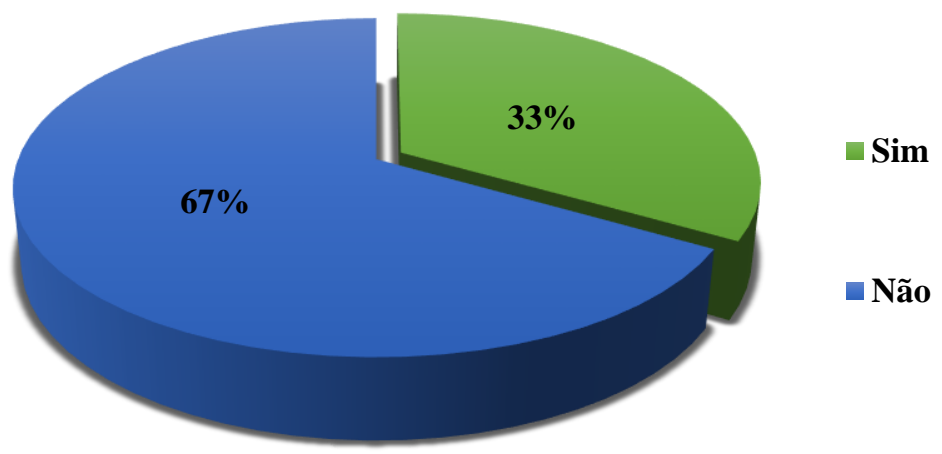

Diante das alternativas sim ou não apresentadas, dos 33 contabilistas entrevistados, $67 \%$ acreditam que não terá maior participação no mercado pelo fato da implantação da NFC-e; já 33\% acreditam que sim, terá maior participação no mercado pelo fato da implantação da NFC-e.

Questionado aos contabilistas das empresas de prestação de serviços contábeis de Tangará da Serra - MT que responderam sim na questão anterior, de qual forma sua empresa de prestação de serviços contábeis conseguirá maior participação no mercado, os resultado são apresentados no gráfico 9 abaixo:

Gráfico 9 - Se sim, de que forma: 


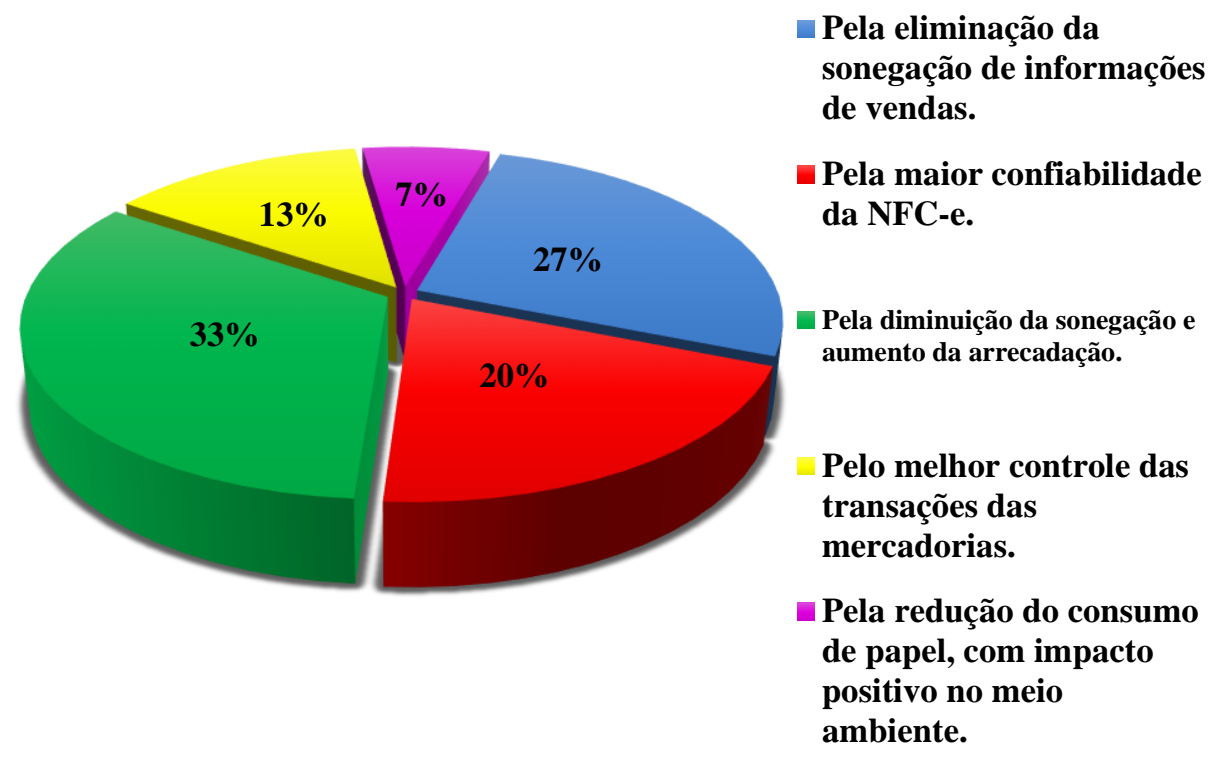

Dos 33 contabilistas entrevistados, 33\% disseram acreditar que terá maior participação no mercado pela diminuição da sonegação e aumento da arrecadação; já $27 \%$ disseram acreditar que terá maior participação no mercado pela eliminação da sonegação de informações de vendas; $20 \%$ responderam que terá maior participação no mercado pela maior confiabilidade da NFC-e; já 13\% responderam que terá maior participação no mercado pelo melhor controle das transações das mercadorias; e apenas $7 \%$ disseram ser pela redução do consumo do papel, com impacto positivo no meio ambiente; Resultados estes, onde demonstram que a maioria dos contabilistas acreditam que terá maior participação no mercado pela diminuição da sonegação e aumento da arrecadação.

Abaixo, demonstra na tabela 3, os resultados das respostas efetuadas por contabilistas responsáveis pelas empresas de serviços contábeis de Tangará da Serra - MT, sobre quais pontos a NFC-e gerou ou poderá gerar benefícios para sua empresa na prestação de serviços contábeis? Disponibilizou-se escala de 1 a 5, onde: 1- Sem Importância (SI); 2Pouca Importância (PI) 3- Neutro (N); 4- Muita Importância (MI) e 5- Extrema Importância (EI).

Nesta questão as alternativas eram: 1) Redução de consumo de papel; 2) Eliminação de arquivos; 3) Redução de erros de escrituração contábil; 4) Redução de tempo na escrituração contábil; 5) Aumento na lucratividade do escritório.

Tabela - 3 em quais pontos a NFC-e gerou ou poderá gerar benefícios para sua empresa na prestação de serviços contábeis?):

\begin{tabular}{|c|c|c|c|c|c|c|c|}
\hline ALTERNATIVAS & $(\mathrm{SI})$ & \multicolumn{1}{c}{$(\mathrm{PI})$} & \multicolumn{1}{c}{$(\mathrm{N})$} & \multicolumn{1}{c}{$(\mathrm{MI})$} & \multicolumn{2}{c}{ TOTAL } \\
\hline 1 & $\mathbf{3 9 , 3 9 \%}$ & $\mathbf{3 0 , 3 0 \%}$ & $\mathbf{3 , 0 3 \%}$ & $\mathbf{9 , 0 9 \%}$ & $\mathbf{1 8 , 1 8 \%}$ & $\mathbf{1 0 0 \%}$ \\
\hline 2 & $\mathbf{1 8 , 1 8 \%}$ & $\mathbf{2 1 , 2 1 \%}$ & $\mathbf{2 1 , 2 1 \%}$ & $\mathbf{1 2 , 1 2 \%}$ & $\mathbf{2 7 , 2 7 \%}$ & $\mathbf{1 0 0 \%}$ \\
\hline 3 & $\mathbf{1 2 , 1 2 \%}$ & $\mathbf{6 , 0 6}$ & $\mathbf{2 1 , 2 1 \%}$ & $\mathbf{1 8 , 1 8 \%}$ & $\mathbf{4 2 , 4 2 \%}$ & $\mathbf{1 0 0 \%}$ \\
\hline 4 & $\mathbf{6 , 0 6 \%}$ & $\mathbf{9 , 0 9 \%}$ & $\mathbf{6 , 0 6 \%}$ & $\mathbf{2 1 , 2 1 \%}$ & $\mathbf{5 7 , 5 8 \%}$ & $\mathbf{1 0 0 \%}$ \\
\hline 5 & $\mathbf{4 8 , 4 8 \%}$ & $\mathbf{6 , 0 6 \%}$ & $\mathbf{1 8 , 1 8 \%}$ & $\mathbf{6 , 0 6 \%}$ & $\mathbf{2 1 , 2 1 \%}$ & $\mathbf{1 0 0 \%}$ \\
\hline
\end{tabular}

A primeira alternativa apresentou um percentual de $69,69 \%$ dos contabilistas que disseram ser sem ou pouca a importância, da redução de custos e consumo de papel, trazer benefícios para sua empresa de prestação de serviços contábeis; 3,03\% estão neutros com relação a está questão; Apenas $27,27 \%$ dos contabilistas disseram que é de muita ou 
extrema importância o benefício que trará para sua empresa de prestação de serviços contábeis, a redução de custos e consumo de papel.

$\mathrm{Na}$ segunda alternativa que refere-se a eliminação de arquivos, podemos nota o equilíbrio das respostas, pois, 39,39\% dos contabilistas acreditam que é sem ou pouca importância; porem com o mesmo percentual de 39,39\% dos contabilistas disseram que é de muita ou extrema importância o benefício que trará a eliminação dos arquivos; e $21,21 \%$ estão neutros com relação a está questão.

A terceira alternativa trata da redução dos erros de escriturações contábeis, $18,18 \%$ dos contabilistas acham sem ou de pouca importância o benefício que terá; $21,21 \%$ estão neutros com relação a está questão; porem $60,60 \%$ dos contabilistas acham de muita ou extrema importância o benefício.

A Quarta alternativa, abordou a questão da redução de tempo na escrituração contábil, 15,15\% dos contabilistas acham sem ou de pouca importância o benefício que terá; $6,06 \%$ estão neutros com relação a está questão; porem $78,79 \%$ dos contabilistas acham de muita ou extrema importância o benefício da redução do tempo na escrituração.

Quinta alternativa perguntou sobre o benefício no aumento da lucratividade do escritório, 54,54\% dos contabilistas acham sem ou de pouca importância o benefício que terá; $18,18 \%$ estão neutros com relação a está questão; $27,27 \%$ dos contabilistas acham de muita ou extrema importância o benefício.

\section{CONSIDERAÇÕES FINAIS}

Pelos resultados da pesquisa, verificou-se que no geral, os contabilistas das empresas de prestação de serviços contábeis de Tangará da Serra - MT acreditam que o novo modelo de NFC-e poderá gerar benefícios tanto para o fisco, os clientes e para o próprio contabilista na execução dos serviços diários. Desde a construção até sua finalização, a pesquisa, esteve focada diretamente, na Nota Fiscal do Consumidor Eletrônica (NFC-e): Percepção da Viabilidade de Utilização junto às empresas prestadoras de serviços contábeis de Tangará da Serra - MT.

Buscou-se, através do método bibliográfico, e por meio de questionário, contextualizar, diagnosticar e analisar os fatores que puderam ou não proporcionar satisfação, dos contabilistas das empresas prestadoras de serviços contábeis de Tangará da Serra - MT com a utilização da NFC-e por seus clientes e seus retornos. A partir disso, respondemos ao problema proposto. Identificamos que a percepção da viabilidade utilização da Nota Fiscal do Consumidor Eletrônica para os contabilistas das empresas prestadoras de serviços contábeis foi satisfatória, conforme demonstrado nos resultados, também podemos afirmar que os contabilistas disseram com relação aos retornos esperados, que a redução do tempo de escrituração e de erros de escrituração, são os itens 
que mais trarão retornos as empresas de prestação de serviços contábeis conforme demonstram os resultados da questão 10 .

Portanto, os objetivos geral e específicos foram atingidos. Os contabilistas em sua maioria demonstram-se satisfeitos com a implantação da NFC-e quanto ao processo de utilização e eventuais retornos na prática contábil, expondo as suas opiniões através dos questionários onde foi possível constatar está satisfação e também constatar as dificuldades e os retornos esperados a partir desta implantação.

Sugere-se como continuação a esta pesquisa, uma nova visita às empresas de prestação de serviços contábeis de Tangará da Serra - MT da amostra e desta vez analisar se a utilização da NFC-e por parte dos seus clientes realmente facilitou a fiscalização por parte do fisco e se houve os retornos esperados conforme apresentados na amostra.

\section{REFERÊNCIAS BIBLIOGRÁFICAS}

AJUSTE SINIEF DO MINISTÉRIO DA FAZENDA. Disponível em www1.fazenda.gov.br/confazl, acesso em 20 de novembro de 2013.

CONSELHO REGIONAL DE CONTABILIDADE DE MATO GROSSO. Disponível em http://crcmt.org.br/site/novo/registro quantos 2.php, LISTA DE ESCRITORIOS INDIVIDUAIS.

http://crcmt.org.br/site/novo/registro quantos 3.php, LISTA DE ESCRITORIOS SOCIEDADES.

Acesso em 22 de Abril de 2014.

DIÓGENES, Antonia Danyelle Batista. A importância da informática na contabilidade. Disponível em: http://www.contabeis.com.br/artigos/75/a-importancia-da-informatica-nacontabilidade/ Acesso em 02/05/2014.

DOSSIÊ NFC-e. Disponível em www.tecnospeed.com.br/nfc-e, acesso em 13 de setembro de 2013.

ANDRADE, M.M. Introdução à Metodologia do trabalho científico. 10. ed. São Paulo: Atlas. 2010.117 p.

GIL, Antônio Carlos. Como Elaborar Projetos de Pesquisa. 4. ed. São Paulo: Atlas, 2002. 175 p.

GIROTTO, Maristela. O Brasil e a adoção do padrão contábil internacional. Revista Brasileira de Contabilidade, Brasília, n. 167, p. 7-19, setembro/outubro 2007.

MARCONI, Marina de Andrade; LAKATOS, Eva Maria. Fundamentos de Metodologia Científica. 5. ed. São Paulo: Atlas, 2003. 311p.

MARQUES, V. A. O Empirismo e a Contabilidade - uma abordagem histórica. Revista Brasileira de Contabilidade, Brasília, n. 162, p. 57-62, novembro/dezembro 2006.

NETO, João Estevão Barbosa; DIAS, Warley de Oliveira; PINHEIRO, Laura Edith Taboada. Impacto da Convergência para as IFRS na Análise Financeira: um estudo em 
empresas brasileiras de capital aberto. Contabilidade Vista \& Revista, Belo Horizonte, v. 20, n. 4, p. 131-153, outubro/dezembro 2009.

SAMPIERI, R.H. Metodologia de pesquisa. Tradução de Fatima Conceição Murad,

Melissa Kassner, Sheila Cara Dystyler Cadeira. 3.ed. São Paulo: Mcgraw-Hill. 2006. 416p.

SECRETARIA DE ESTADO E FAZENDA DE MATO GROSSO. Disponível em Www.sefaz.mt.gov.br, acesso em 13 de setembro de 2013.

SEVERINO, A.J. Metodologia do trabalho científico. 22. ed. rev. e ampl. de acordo com a ABNT- São Paulo: Cortez, 2002. 162 p.

TECNOSPEED DOSSIÊ NFC-e. Disponível em www.tecnospeed.com.br, acesso em 13 de setembro 2013. 


\section{APÊNDICE A - CARTA DE APRESENTAÇ̃̃o}

\section{Prezados (as) CONTADORES (as),}

Esta é uma pesquisa de Graduação da UNEMAT (Universidade do Estado de Mato Grosso) campus universitário de Tangará da Serra, curso de Ciências Contábeis, a fim de demonstrar a percepção da viabilidade de utilização da Nota Fiscal de Consumidor Eletrônica (NFC-e), nos serviços prestados por empresas de serviços contábeis de Tangará da Serra - MT.

A sua participação é fundamental para o avanço desta pesquisa, auxiliando a universidade a tornar o ensino do acadêmico mais adequado ao mercado de trabalho.

Saiba que tem o direito de não responder a alguma pergunta, qualquer que seja o motivo. Lembramos que não existem respostas certas ou erradas, o que importa é sua opinião sincera. Caso não responda ou não opine, peço que sinalize a alternativa correspondente para que possa ter certeza de que não se esqueceu de responder a alguma pergunta.

Lembramos que nenhum dado será divulgado individualmente. Todas as informações serão tabuladas e agrupadas para análise.

Muito Obrigado pela sua participação.

Ronison Rodrigues da Costa

Graduando
Márcio Iris de Morais

Coordenador da pesquisa 
APÊNDICE B - INSTRUMENTO DE COLETA

1. Algum(s) cliente(s) de sua empresa utiliza Nota Fiscal de Consumidor Eletrônica (NFC-e)?

( ) Sim.

( ) Não.

2. Qual o principal motivo da implantação da NFC-e na(s) empresa(s) do(s) seu(s) cliente(s)?
( ) Obrigatoriedade.
( ) Voluntariedade.
( ) Sistematização dos dados.
( ) Diminuição de gastos.
( ) Outros.

3. Com a utilização ou possibilidade de utilizar a NFC-e por parte do(s) cliente(s), através do arquivo XML (Extensible Markup Language) disponibilizado, acredita que facilita ou facilitará a execução dos lançamentos fiscais e contábeis para o profissional contábil?

( ) Sim, pois reduz-se tempo na execução dos serviços, bem como, erros de escrituração, devido à importação automática do arquivo XML.

( ) Não, por falta de adaptação do sistema utilizado pelo escritório contábil para importar e extrair as informações do arquivo XML.

4. Classifique de 1 a 5 para o(s) cliente(s), os impactos com a implantação da NFC-e. Sendo: 1- Sem Importância (SI); 2- Pouca Importância (PI) 3- Neutro (N); 4- Muita Importância (MI) e 5- Extrema Importância (EI).

( ) Consumo de papel será reduzido com impacto positivo ao meio Ambiente.

( ) Oportunidade de empregos na área de tecnologia em informática.

( ) Facilitou a fiscalização, aumentando a arrecadação de impostos e diminuindo a sonegação.

( ) Diminuiu os custos com equipamentos emissor de Cupom Fiscal.

( ) Não houve benefícios.

5. Sua empresa de prestação de serviços contábeis encontrou ou acredita que encontrará dificuldade(s) na utilização da NFC-e disponibilizada por seu(s) cliente(s)?
( ) Sim.
( ) Não.

6. Se sim, qual procedimento teve mais dificuldade(s):

( ) Importação para o sistema contábil. 

( ) Emissão de NFC-e.
( ) Manuseio ou Operacionalização.
( ) Falta de informação.
( ) Outros?

7. Classifique de 1 a 5 , a dificuldade que o profissional da contabilidade tem ou terá com a implantação da NFC-e ao(s) cliente(s): Sendo: 1- Sem Dificuldade (SD); 2Pouca Dificuldade (PD) 3- Neutro (N); 4- Muita Dificuldade (MD) e 5- Extrema Dificuldade (ED).

( ) Aumento das obrigações acessórias.

( ) Investir em tecnologia para o escritório.

( ) Qualificação contínua dos colaboradores também na área de informação, sistemas e novas tecnologias.

( ) Tarefa implícita de repassar as normatizações da NFC-e aos clientes, além de auxiliar os microempresários na adequação da implantação da NFC-e.

( ) Conhecimento constante das alterações ocorridas na legislação.

8. Com a utilização da NFC-e, acredita que sua empresa de prestação de serviços contábeis conseguirá maior participação no mercado?
( ) Sim
( ) Não

9. Se sim, de que forma:

( ) Pela eliminação da sonegação de informações de vendas.

( ) Pela maior confiabilidade da NFC-e.

( ) Pela diminuição da sonegação e aumento da arrecadação.

( ) Pelo melhor controle das transações das mercadorias.

( ) Pela redução do consumo de papel, com impacto positivo no meio ambiente

10. Classifique de 1 a 5, em quais pontos a NFC-e gerou ou poderá gerar benefícios para sua empresa na prestação de serviços contábeis? Sendo: 1- Sem Importância (SI); 2- Pouca Importância (PI) 3- Neutro (N); 4- Muita Importância (MI) e 5Extrema Importância (EI).

( ) Redução de custos e consumo de papel.

( ) Eliminação de arquivos.

( ) Redução de erros de escrituração contábil.

( ) Redução de tempo na escrituração contábil.

( ) Aumento na lucratividade do escritório. 